\title{
Development of a Lyophilized Formulation of Pegaspargase and Comparability Versus Liquid Pegaspargase
}

\author{
Alexander M. Faschinger · Nicole Sessler
}

Received: April 1, 2019 / Published online: May 28, 2019

(C) The Author(s) 2019

with storage under refrigerated conditions $\left(2-8^{\circ} \mathrm{C}\right)$.

Conclusions: Lyophilization improved the stability of pegaspargase without altering other physicochemical properties, permitting a prolonged shelf life of at least 2 years when stored at $2-8{ }^{\circ} \mathrm{C}$. This may enable greater storage flexibility and allow for better management of pegaspargase.

Funding: Study Sponsor: Baxalta (now part of Takeda). Publication Sponsor: Servier Affaires Médicales.

Keywords: Cancer chemotherapy; Enzymes; Formulation; Lyophilization; Pediatric; Pegylation; Stability; Stabilization

\section{INTRODUCTION}

The treatment of acute lymphoblastic leukemia (ALL) involves the administration of multiple chemotherapeutic agents, typically including an asparaginase agent to deplete serum L-asparagine levels [1-3]. L-Asparaginase may be derived from Escherichia coli (E. coli asparaginase) or isolated from Erwinia chrysanthemi (Erwinase $^{\circledR}$, Jazz Pharmaceuticals; Erwinia asparaginase; crisantaspase) [4-10]. Modified forms of E. coli asparaginase with improved pharmacological properties have been developed, including pegylated E. coli asparaginase (Oncaspar $^{\circledR}$ [pegaspargase], Servier) [11]. A 
recombinant asparaginase (Spectrila ${ }^{\circledR}$, medac Pharma) is also available, and pegylated forms of recombinant enzymes are in development (MC0609; pegcrisantaspase) [12-14]. Pegaspargase is used as a first-line treatment for ALL in clinical practice, whereas crisantaspase is generally employed following failure of E. coliderived asparaginases due to immunological reactions [15].

Pegylation of E.coli asparaginase confers advantages over the native enzyme, including prolonged half-life [16-18], which leads to reduced immunogenicity $[17,19]$ and reduced frequency of administration (every 2 weeks versus twice to three times weekly). In a comparative study of native E. coli asparaginase versus pegaspargase in children with ALL, significantly lower proportions of patients treated with pegaspargase had elevated anti-asparaginase antibody ratios compared with those receiving native E. coli asparaginase. The difference was most notable during the first delayed intensification phase (following previous exposure to treatment during the induction phase): over $40 \%$ of patients treated with native E. coli asparaginase, compared with $11 \%$ of those receiving pegaspargase, had antibody ratios greater than 1.5 times the negative control. High antibody titers had been associated with low asparaginase activity in previous studies, and antibody ratios greater than 1.5 were associated with low asparaginase activity in patients receiving native E. coli asparaginase [19]. However, in patients receiving pegaspargase, none of the samples with antibody ratios of 1.5 or greater were associated with low asparaginase activity, suggesting that pegaspargase was not neutralized or cleared more rapidly when antibody levels were elevated [19].

Pegaspargase is a conjugated enzyme, with polyethylene glycol (PEG) covalently bound to L-asparaginase via an ester linkage. Hydrolytic instability has been observed in vitro [20], leading to potential for depegylation if the ester bond undergoes hydrolysis. Similar to other pegylated pharmaceuticals [21, 22], pegylation increases steric hindrance of the active site on L-asparaginase; consequently, the native or depegylated product has greater enzymatic activity than the pegylated product, as well as a shorter half-life [20]. The shelf life of pegaspargase is limited to 8 months [23].

It is therefore important to understand the stability of new pegylated asparaginase preparations, as this may impact many factors including shelf life [20]. Since depegylation results from hydrolysis of the ester bond linking PEG to L-asparaginase [20], removal of water from the formulation by lyophilization (freezedrying) is a rational approach to improve stability of the pegylated product and is a widely used method to improve the long-term storage stability of biopharmaceuticals [24].

The freezing and drying processes involved in lyophilization can themselves impose stresses on proteins [24]. One potential consequence of such stress is protein aggregation [25], forming subvisible particles in the reconstituted solution, which can lead to increased immunogenicity $[26,27]$. Stabilizing agents, such as sucrose or sorbitol, have been shown to reduce the subvisible particle load in reconstituted lyophilized solutions of immunoglobulins [25, 28], and are typically included among excipients used in the production of lyophilized drug products [24].

Product quality testing is therefore important to ensure that the lyophilized product gains the desired property of improved stability, without incurring detrimental effects, such as changes in activity or increased propensity to form protein aggregates. A comprehensive series of analytical methods must be employed to determine properties of the lyophilized cake and behavior of the protein upon reconstitution as a solution for injection/administration [24]. This article describes the development process that has been used to produce a lyophilized form of pegaspargase, and provides a comparative assessment of structure, potency, quality and purity of the lyophilized and liquid formulations, in addition to exploring optimum storage conditions for lyophilized pegaspargase.

\section{METHODS}

\section{Compliance with Ethics Guidelines}

This article does not contain any studies with human participants or animals. 


\section{Drug Substance Composition}

Lyophilized pegaspargase contains largely the same constituents as liquid pegaspargase, although quantities of some excipients are reduced in the lyophilized formulation, including dibasic sodium phosphate, monobasic sodium phosphate and sodium chloride, and sucrose is added to the lyophilized formulation as a stabilizing agent (Table 1). Both formulations contain $750 \mathrm{U} / \mathrm{mL}$ pegaspargase, following reconstitution of the lyophilized formulation with $5.2 \mathrm{~mL}$ sterile water for injection per vial.

\section{Development Process}

The development process for the bulk drug substance, for both formulations, comprises the following stages: pegylation, clarification, diafiltration, dilution and filtration/sterile filtration (Fig. 1). Initially, L-asparaginase solution is prepared in phosphate buffer at a concentration of $5 \mathrm{mg} / \mathrm{mL}$. In the pegylation step, the native enzyme is chemically modified by reaction of monomethoxypolyethylene glycol succinimidyl succinate (SS-PEG) with primary amines on the protein, producing a pegylated protein with $\mathrm{N}$-hydroxysuccinimide (NHS) as a by-product. The impurities, NHS and any unbound PEG, are removed during the diafiltration step, in which the solution is passed through a membrane with a nominal molecular weight cut-off of $100 \mathrm{kDa}$, allowing impurities through while retaining the pegylated protein product.

Modification of the liquid pegaspargase development process leads to production of a concentrated solution for lyophilization, which allows for final formulation with sucrose to the correct concentration. This modification occurs during the diafiltration step, during which the pegaspargase bulk solution for lyophilization is concentrated to a protein level $(20 \mathrm{mg} / \mathrm{mL})$ three times higher than in the liquid form $(6.5 \mathrm{mg} / \mathrm{mL})$. Following dilution, there is a filtration step and plastic bag fill for the lyophilization bulk solution (with a hold time of $\leq 60$ days before lyophilized product manufacture, determined by the time required for transport to another facility for downstream processing) compared with a direct stainless steel tank fill for the liquid product (hold time of $\leq 72 \mathrm{~h}$ before liquid formulation manufacture). Specifications for the drug substance produced for each formulation are shown in Table 2.

As well as threefold higher protein concentration and enzyme activity in the bulk drug substance for lyophilized pegaspargase, threefold higher levels of impurities (free 10K PEG, total free PEG [the sum of 5K and 10K PEG] and NHS) are permitted in the more concentrated drug substance. In the drug product, prefill

Table 1 Constituents of liquid and lyophilized formulations of pegaspargase

\begin{tabular}{llll}
\hline Component & Function & \multicolumn{2}{l}{ Pegaspargase formulation/amount per mL } \\
\cline { 3 - 4 } & & Liquid & Lyophilized $^{\mathbf{a}}$ \\
\hline Pegaspargase drug substance & Active ingredient & $750 \mathrm{U}$ & $750 \mathrm{U}$ \\
Dibasic sodium phosphate & Buffering agent & $5.58 \mathrm{mg}$ & $2.79 \mathrm{mg}$ \\
Monobasic sodium phosphate & Buffering agent & $1.20 \mathrm{mg}$ & $0.60 \mathrm{mg}$ \\
Sodium chloride & Tonicity & $8.50 \mathrm{mg}$ & $4.25 \mathrm{mg}$ \\
Sucrose & Lyoprotectant (stabilizing agent) & N/A & $45 \mathrm{mg}$ \\
Water for injection & Solvent & QS to $1.0 \mathrm{~g}$ & QS to $1.0 \mathrm{~g}$ \\
\hline
\end{tabular}

$Q S$ quantify sufficient to produce total mass of $1.0 \mathrm{~g}, N / A$ not applicable

${ }^{a}$ Values following reconstitution with water for injection 
Liquid pegaspargase

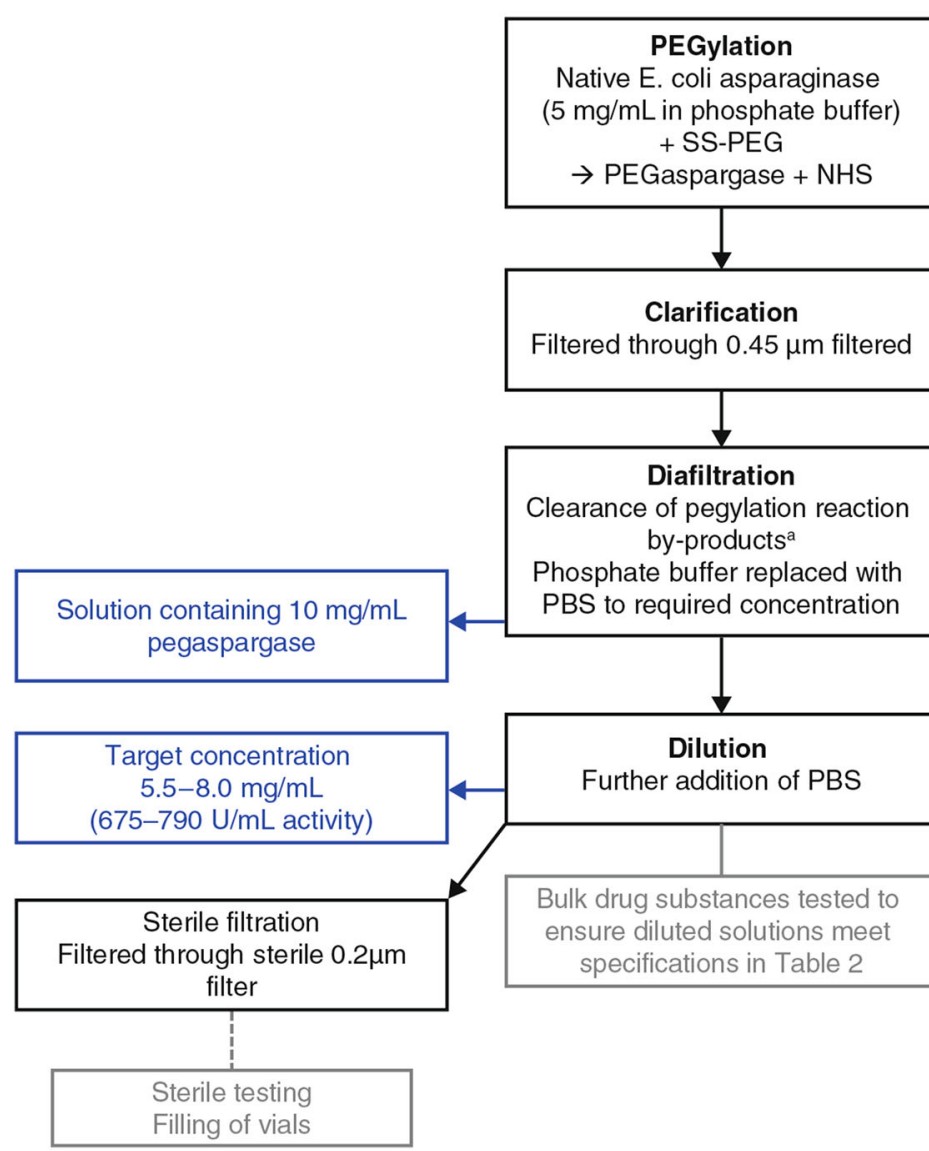

\section{Lyophilized pegaspargase}

Solution containing $25 \mathrm{mg} / \mathrm{mL}$ pegaspargase

Target concentration $18.0-23.6 \mathrm{mg} / \mathrm{mL}$ (target $20 \mathrm{mg} / \mathrm{mL}$ ) (1850-3020 U/mL activity)
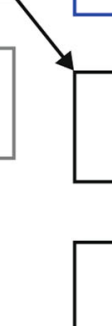

Filtered through $0.2 \mu \mathrm{m}$ filter

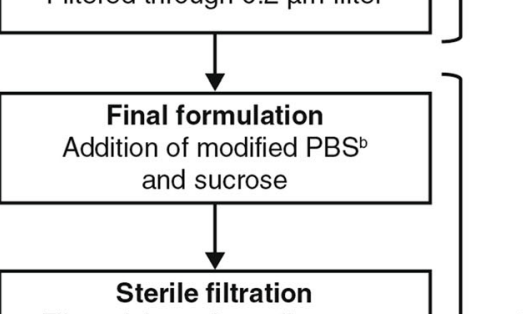

\begin{tabular}{|c|}
\hline Aseptic filling of vials \\
\hline Lyophilization \\
\hline Thermal treatment phase \\
\hline $\begin{array}{c}\text { Freezer condenser and } \\
\text { evacuator phase }\end{array}$ \\
\hline Primary dry phase \\
\hline $\begin{array}{c}\text { Secondary dry phase } \\
\text { I }\end{array}$ \\
\hline $\begin{array}{c}\text { Stoppering of vials } \\
\text { within lyophilization } \\
\text { chamber }\end{array}$ \\
\hline
\end{tabular}


4 Fig. 1 Development process for liquid and lyophilized pegaspargase. Black boxes represent core process steps; grey boxes show intermediate steps and tests; blue boxes highlight different pegaspargase concentrations in drug substance for liquid and lyophilized pegaspargase. ${ }^{a}$ Free PEG, 10K PEG, NHS. ${ }^{\mathrm{b}}$ Dibasic and monobasic sodium phosphate and sodium chloride at half the concentrations of PBS used for production of bulk drug substance/liquid pegaspargase. NHS $N$-hydroxysuccinimide, PBS phosphate buffered saline, SS-PEG monomethoxypolyethylene glycol succinimidyl succinate

target weight for the lyophilized cake is $2.5 \mathrm{~g}$, which is reconstituted with $5.2 \mathrm{~mL}$ of sterile water for injections. This restores impurities to the concentrations permitted in liquid pegaspargase following reconstitution as a solution for administration.

For liquid pegaspargase, the final step in the development process is sterile filtration-the drug substance is filtered through a sterile 0.2 $\mu \mathrm{m}$ filter into a jacketed stainless steel vessel and stored at $2-8{ }^{\circ} \mathrm{C}$ for a maximum of $72 \mathrm{~h}$ before it is aliquoted into sterile vials. For lyophilized pegaspargase, the concentrated drug substance is filtered through a $0.2 \mu \mathrm{m}$ filter into a presterilized $20 \mathrm{~L}$ bulk solution bag, in which it is stored at $2-8{ }^{\circ} \mathrm{C}$ for a maximum of 60 days, prior to the final formulation, sterile filtration and lyophilization process steps (Fig. 1). Samples were monitored at $0,2,4,6,8$ and 12 weeks to assess the stability of pegaspargase during refrigerated storage as liquid concentrated bulk drug substance.

The final formulation process for lyophilized pegaspargase involves addition of a buffer containing sucrose as a lyoprotectant/stabilizing agent, plus dibasic sodium phosphate, monobasic sodium phosphate and sodium chloride (all buffer components apart from sucrose are present in the standard phosphate buffered saline [PBS] used for liquid pegaspargase but in different concentrations) (Table 1). The resulting solution contains pegaspargase at two times the concentration of liquid pegaspargase, as the higher concentration (lower water content) reduces the time required for freeze/drying cycles during the lyophilization process. This solution undergoes sterile filtration, after which vials are filled in aseptic conditions prior to lyophilization.

The lyophilization process comprises a thermal treatment phase and a freeze condenser and evacuator phase. On completion of the lyophilization process, the evacuated lyophilization chamber is backfilled with nitrogen gas and the vials are stoppered and crimp sealed. Lyophilization process cycle parameters are shown in Supplementary Table 1.

\section{Comparability Assessment}

A series of comparability tests were performed on samples of liquid pegaspargase and reconstituted lyophilized pegaspargase. Prior to testing, vials of lyophilized pegaspargase were reconstituted with a 21-gauge needle by dispensing $5.2 \mathrm{~mL}$ of sterile water for injection into each vial and mixing for 5 min or until particles of lyophilized cake were no longer visible by visual inspection at approximately 50 rotations per minute (rpm) on a roller mixer. Comparability tests were conducted on three lots each of liquid and lyophilized pegaspargase, to ensure that consistent results were replicated and permit statistical analysis.

\section{Assessment of Physiochemical Properties and Critical Quality Attributes}

Physicochemical properties and critical quality attributes of each lot were assessed to determine if batches of liquid pegaspargase and reconstituted lyophilized pegaspargase met predefined acceptance criteria (as detailed in Table 3). Acceptance criteria for the liquid product, including control limits for appearance, $\mathrm{pH}$, protein concentration, activity, free PEG, etc. were established on the basis of a large number of historical lots of liquid pegaspargase, and were similar to the specifications for bulk drug substance (as detailed in Table 2). Similarly, acceptance criteria suitable for a lyophilized product were established on the basis of those for liquid pegaspargase to assess and determine the suitability of such a product based on physicochemical properties and critical quality attributes. 


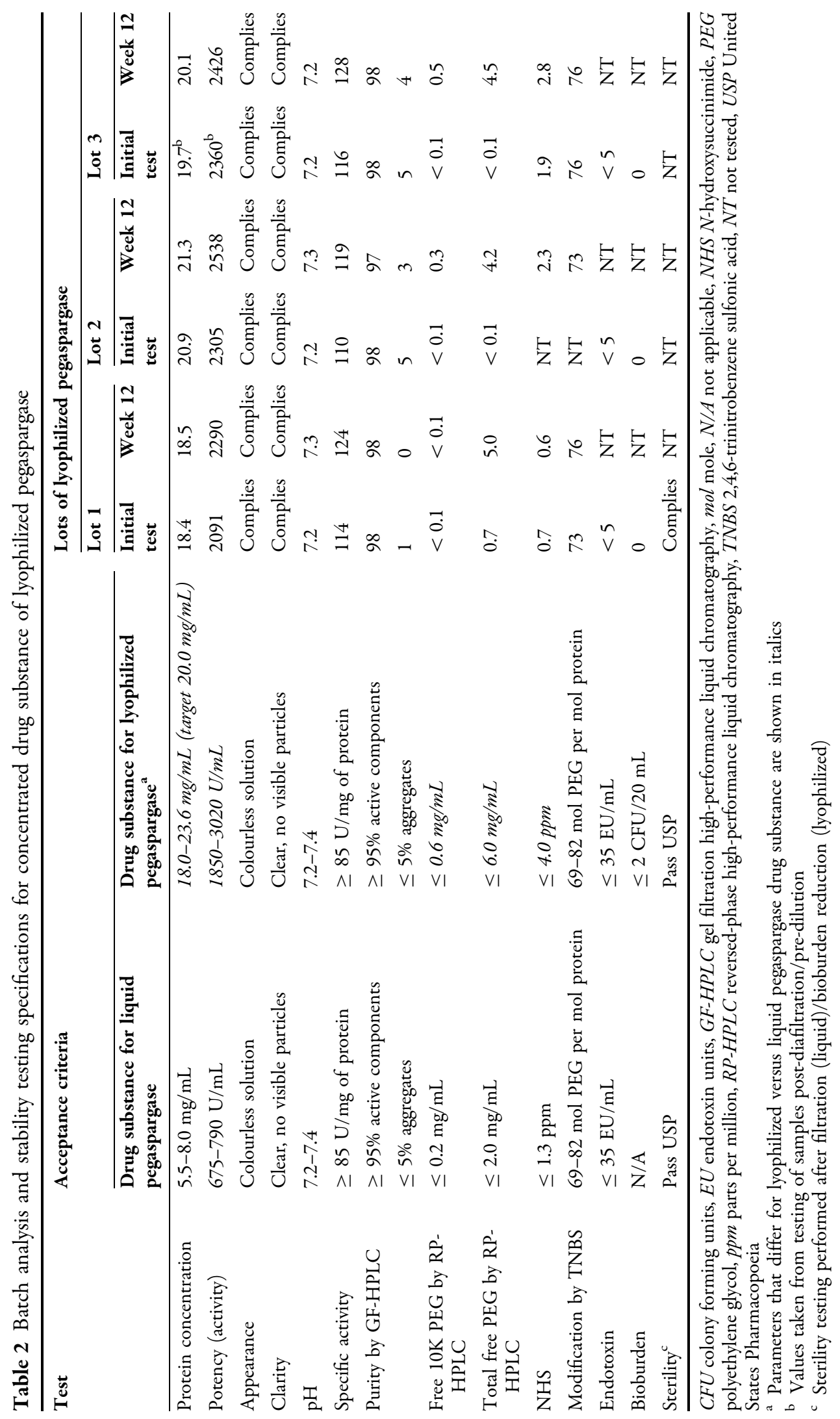




\section{Characterization Tests}

A series of tests was performed to characterize higher-order protein structure and other aspects of liquid and lyophilized pegaspargase formulations. In most cases, characterization tests were conducted side-by-side on paired lots of liquid and lyophilized pegaspargase to permit direct comparison. Tests included the following: characterization of molecular mass, using matrix-assisted laser desorption ionization time-of-flight (MALDI-TOF); extent of pegylation, measured using size-exclusion chromatography with multi-angle static light scattering (SEC-MALS) and high-performance liquid chromatography-mass spectrometry (HPLC-MS); purity, assessed by sodium dodecyl sulfate polyacrylamide gel electrophoresis (SDSPAGE) profiles; calorimetric enthalpy and transition peak midpoint (melting temperature), assessed by differential scanning calorimetry (DSC); and secondary and tertiary protein structure motifs and thermal unfolding characteristics, investigated by performing circular dichroism (CD) spectroscopy at various wavelengths. Further details of the analytical methods used in the characterization tests are detailed in the Supplementary Methods section.

In vitro enzyme kinetics were also evaluated. Pegaspargase was added to asparagine, diluted in buffer at $\mathrm{pH} 7.3$ to a range of concentrations $(5-250 \mu \mathrm{M})$. After addition of the derivatization reagent, and a second dilution step, the samples were incubated at $37^{\circ} \mathrm{C}$ for $15 \mathrm{~min}$ to allow the enzymatic reaction to proceed. The released aspartic acid was derivatized before measurement by reversed-phase HPLC (RP-HPLC). The results obtained from this range of concentrations were used to determine enzyme kinetic parameters including Michaelis constant catalytic rate constant and maximum velocity.

\section{Forced Degradation Studies}

Degradation profiles for each formulation were determined in forced degradation studies in order to evaluate the comparative stress stability behavior of each pegaspargase formulation. The effect of heat stress was evaluated in samples stored at $40 \pm 2{ }^{\circ} \mathrm{C}$ (in $75 \pm 5 \%$ relative humidity $[\mathrm{RH}]$ ) for 6 months. The effects of changes in $\mathrm{pH}$ were tested by applying acid/base stress sufficient to induce 5-25\% degradation. For acid stress, $200 \mu \mathrm{L} 0.8 \mathrm{M} \mathrm{HCl}$ or $200 \mu \mathrm{L}$ $0.4 \mathrm{M} \mathrm{HCl}$ were added to $20 \mathrm{~mL}$ liquid or reconstituted lyophilized pegaspargase, respectively, and samples were incubated at $37^{\circ} \mathrm{C}$ for $90 \mathrm{~min}$. For base stress, $200 \mu \mathrm{L} 0.8 \mathrm{M} \mathrm{NaOH}$ or $200 \mu \mathrm{L} 0.4 \mathrm{M} \mathrm{NaOH}$ were added to $20 \mathrm{~mL}$ liquid or reconstituted lyophilized pegaspargase, respectively, and samples were incubated at $37^{\circ} \mathrm{C}$ for $20 \mathrm{~min}$. The concentration of $\mathrm{HCl}$ and $\mathrm{NaOH}$ used in the stress tests were different for the liquid and reconstituted lyophilized pegaspargase because of the constitution of the different formulations. As the lyophilized cake is unstable at commercial liquid pegaspargase concentrations, the filled product for lyophilization is approximately double that of commercial pegaspargase, resulting in reduced concentration of stabilizing salts upon reconstitution. Therefore, half the concentrations of $\mathrm{HCl}$ and $\mathrm{NaOH}$ are required for the same $\mathrm{pH}$ to be reached because only half the stabilizing buffer is present in reconstituted lyophilized pegaspargase. Oxidative stress was applied by adding $200 \mu \mathrm{L} 30 \% \mathrm{H}_{2} \mathrm{O}_{2}$ to $20 \mathrm{~mL}$ pegaspargase and incubating at $40{ }^{\circ} \mathrm{C}$ for $30 \mathrm{~min}$. Agitation stress was applied to inverted vials shaken at $120 \mathrm{rpm}$, using an orbital shaker, for $8 \mathrm{~h}$ at room temperature. Light (photo) stress involved exposure to 1.2 million Lux $\mathrm{h}$ cool white or $200 \mathrm{~W}$ h ultraviolet (UV) light. Critical quality attributes including purity, potency, aggregates and total free PEG were tested at various time points during or after exposure to stresses.

\section{Stability Tests}

Long-term stability of lyophilized pegaspargase was assessed for at least 3 years for samples stored under refrigerated $\left(5 \pm 3{ }^{\circ} \mathrm{C}\right)$ and accelerated $\left(25 \pm 2{ }^{\circ} \mathrm{C} ; 60 \pm 5 \% \mathrm{RH}\right)$ conditions. Purity, potency and aggregates were measured in reconstituted samples (every 3 months for the first year and every 6 months thereafter). One method was used to determine the purity of active non-aggregated proteins, measured by gel-filtration HPLC (GF-HPLC), and the number of aggregated non-active proteins. Activity was measured as an indicator of potency by RP- 
Table 3 Assessment of physicochemical properties and critical quality attributes

\begin{tabular}{|c|c|c|c|}
\hline Test & Acceptance criteria & Liquid pegaspargase $^{a}$ & $\begin{array}{l}\text { Reconstituted lyophilized } \\
\text { pegaspargase }^{\mathrm{a}}\end{array}$ \\
\hline Appearance & Colourless solution $^{\mathrm{b}}$ & Complies & Complies \\
\hline Clarity & Clear, no visible particles & Complies & Complies \\
\hline Fill volume & To deliver $5.0 \mathrm{~mL}$ & $5.1-5.2 \mathrm{~mL}$ & $5.2-5.5 \mathrm{~mL}$ \\
\hline $\mathrm{pH}$ & $7.2-7.4$ & $7.2-7.3$ & 7.4 \\
\hline $\begin{array}{l}\text { Protein } \\
\text { concentration }\end{array}$ & $4.5-8.5 \mathrm{mg} / \mathrm{mL}$ & $6.2-7.3 \mathrm{mg} / \mathrm{mL}$ & $6.5-7.1 \mathrm{mg} / \mathrm{mL}$ \\
\hline Potency (activity) & $600-900 \mathrm{U} / \mathrm{mL}$ & $737-778 \mathrm{U} / \mathrm{mL}$ & $718-805 \mathrm{U} / \mathrm{mL}$ \\
\hline Specific activity & $\geq 85 \mathrm{U} / \mathrm{mg}$ protein & $101-125 \mathrm{U} / \mathrm{mg}$ protein & $111-114 \mathrm{U} / \mathrm{mg}$ protein \\
\hline \multicolumn{4}{|l|}{ Purity by GF-HPLC } \\
\hline $\begin{array}{l}\text { Active } \\
\text { components }\end{array}$ & $\geq 95 \%$ & $98-99 \%$ & $97 \%$ \\
\hline Aggregates & $\leq 8 \%$ & $1-4 \%$ & $1-5 \%$ \\
\hline Free $10 \mathrm{~K}$ PEG & $\leq 0.2 \mathrm{mg} / \mathrm{mL}$ & $<0.07 \mathrm{mg} / \mathrm{mL}$ & $0.1-0.2 \mathrm{mg} / \mathrm{mL}$ \\
\hline Total free PEG & $\leq 2.0 \mathrm{mg} / \mathrm{mL}$ & $0.2-0.6 \mathrm{mg} / \mathrm{mL}$ & $0.5-1.3 \mathrm{mg} / \mathrm{mL}$ \\
\hline NHS & $\leq 2.0 \mathrm{ppm}$ & $0.2-0.6 \mathrm{ppm}$ & $0.2-1.0 \mathrm{ppm}$ \\
\hline $\begin{array}{l}\text { Modification by } \\
\text { TNBS }\end{array}$ & 69-82 mol PEG/mole protein & $\begin{array}{l}\text { 73-75 } \mathrm{mol} \mathrm{PEG} / \mathrm{mole} \\
\text { protein }\end{array}$ & 75-77 mol PEG/mole protein \\
\hline Particulate matter & Per container & & \\
\hline$\geq 2 \mu \mathrm{m}$ & $\leq 27,000$ particles & $1961-3204$ & $530-5834$ \\
\hline$\geq 10 \mu \mathrm{m}$ & $\leq 6000$ particles & $13-46$ & $12-116$ \\
\hline$\geq 25 \mu \mathrm{m}$ & $\leq 600$ particles & 0 & $1-2$ \\
\hline Sterility & Pass USP sterility test & Complies & Complies $^{c}$ \\
\hline General safety & $\begin{array}{l}\text { Pass USP tests in guinea pigs and } \\
\text { mice }\end{array}$ & Conforms & Conforms ${ }^{c}$ \\
\hline Endotoxin by LAL & $\leq 35 \mathrm{EU} / \mathrm{mL}$ & $<15 \mathrm{EU} / \mathrm{mL}$ & $<4 \mathrm{EU} / \mathrm{mL}$ \\
\hline Content uniformity & - & $\mathrm{N} / \mathrm{A}$ & Complies \\
\hline Reconstitution time & $\leq 3 \min$ & $\mathrm{N} / \mathrm{A}$ & $<1 \min$ \\
\hline Water (by KF) & $\leq 3.0 \%$ & $\mathrm{~N} / \mathrm{A}$ & $0.1-0.2 \%$ \\
\hline
\end{tabular}

GF-HPLC gel filtration high-performance liquid chromatography, KF Karl Fischer titration, $L A L$ Limulus amebocyte lysate, $N / A$ not applicable, NHS $N$-hydroxysuccinimide, $P E G$ polyethylene glycol, $p p m$ parts per million, TNBS 2,4,6trinitrobenzene sulfonic acid, USP United States Pharmacopeia Convention

${ }^{a}$ Range of values for three lots tested

b Lyophilized product has appearance of white to off-white cake prior to reconsitution

${ }^{c}$ Sterility and general safety tests not performed for one of the three lots tested 
HPLC. This is assessed by incubating the sample with L-asparagine to generate L-aspartic acid by enzymatic reaction. The amount of released $\mathrm{L}-$ aspartic acid is analysed by RP-HPLC fitted with a UV detector set at $265 \mathrm{~nm}$. This method is also used to determine the identity of the drug substance. Residual water was measured by Karl Fischer titration in samples of lyophilized cake at the same time points.

\section{RESULTS}

\section{Pre-Lyophilization Tests on Bulk Drug Substance}

In this comparability study, all batches of bulk drug substance (concentrated liquid) used in the development process of lyophilized pegaspargase met the required pre-specified criteria detailed in Table 2 , including protein concentration, potency, appearance, $\mathrm{pH}$ and purity. Stability testing showed that storage of bulk drug substance for lyophilized pegaspargase at $2-8{ }^{\circ} \mathrm{C}$ for up to 12 weeks prior to lyophilization met the acceptance criteria approved for liquid pegaspargase (Table 2 and additional time point data shown in Supplementary Tables 2-4). No significant changes in purity were detected, although higher potency, total free PEG and 10K PEG were observed as a result of expected depegylation. However, these elevated results were still within specification limits (Table 2).

\section{Post-Lyophilization Tests on Lyophilized and Reconstituted Lyophilized Pegaspargase}

Tests investigating the physiochemical properties and critical quality attributes of each formulation showed no significant differences between liquid and lyophilized pegaspargase. All parameters, including measures of potency and purity, were within acceptance criteria limits (Table 3).

Characterization tests indicated no significant differences in molecular weight, extent and site of pegylation, and enzyme kinetics. The results of these methods met predefined acceptance criteria (Table 4). However, results of DSC and CD spectroscopy demonstrated that lyophilized pegaspargase has a trend towards lower calorimetric enthalpy required for the transition to an unfolded state, relative to liquid pegaspargase (Table 4 footnotes).

The degradation profile of lyophilized pegaspargase under conditions of heat stress was decelerated compared with liquid pegaspargase. Deleterious changes in purity, potency, aggregates and free PEG were observed to be more rapid in liquid than lyophilized pegaspargase (Fig. 2). Additional stress conditions tested (photo, agitation and acidic, basic and oxidative stress) showed no significant differences in degradation of liquid and lyophilized pegaspargase (Supplementary Tables 5-7).

Stability tests showed that purity, potency, aggregates and residual water in lyophilized cake remained within acceptance criteria limits for samples stored at both $5{ }^{\circ} \mathrm{C}$ and at $25^{\circ} \mathrm{C}$ for up to 3 years. Refrigerated conditions were more favorable for maintained stability of lyophilized pegaspargase. Stability profiles over 45 months showed an expected gradual decline in purity that was slower for samples stored at $5{ }^{\circ} \mathrm{C}$ than $25^{\circ} \mathrm{C}$ (Fig. 3a). Potency (activity) remained constant beyond 3 years in samples at $5^{\circ} \mathrm{C}$, while the decline in purity at $25^{\circ} \mathrm{C}$ corresponded with a decrease in specific activity at this temperature (Fig. 3b). Aggregates remained at a constantly low level in samples at $5{ }^{\circ} \mathrm{C}$, whereas increased aggregation was observed in samples at $25^{\circ} \mathrm{C}$ (Fig. 3c). There was minimal increase in residual water in the lyophilized cake at $5{ }^{\circ} \mathrm{C}$, while increased residual water was observed at $25^{\circ} \mathrm{C}$ (RH 60\%) (Fig. 3d). On the basis of these long-term stability results, the shelf life of lyophilized pegaspargase was set as 24 months at $5 \pm 3{ }^{\circ} \mathrm{C}$.

\section{DISCUSSION}

The lyophilization process described here produced a pegaspargase formulation with comparable physicochemical properties, purity and potency profiles to those of liquid pegaspargase. Ongoing process validation showed no significant differences in quality attributes between 


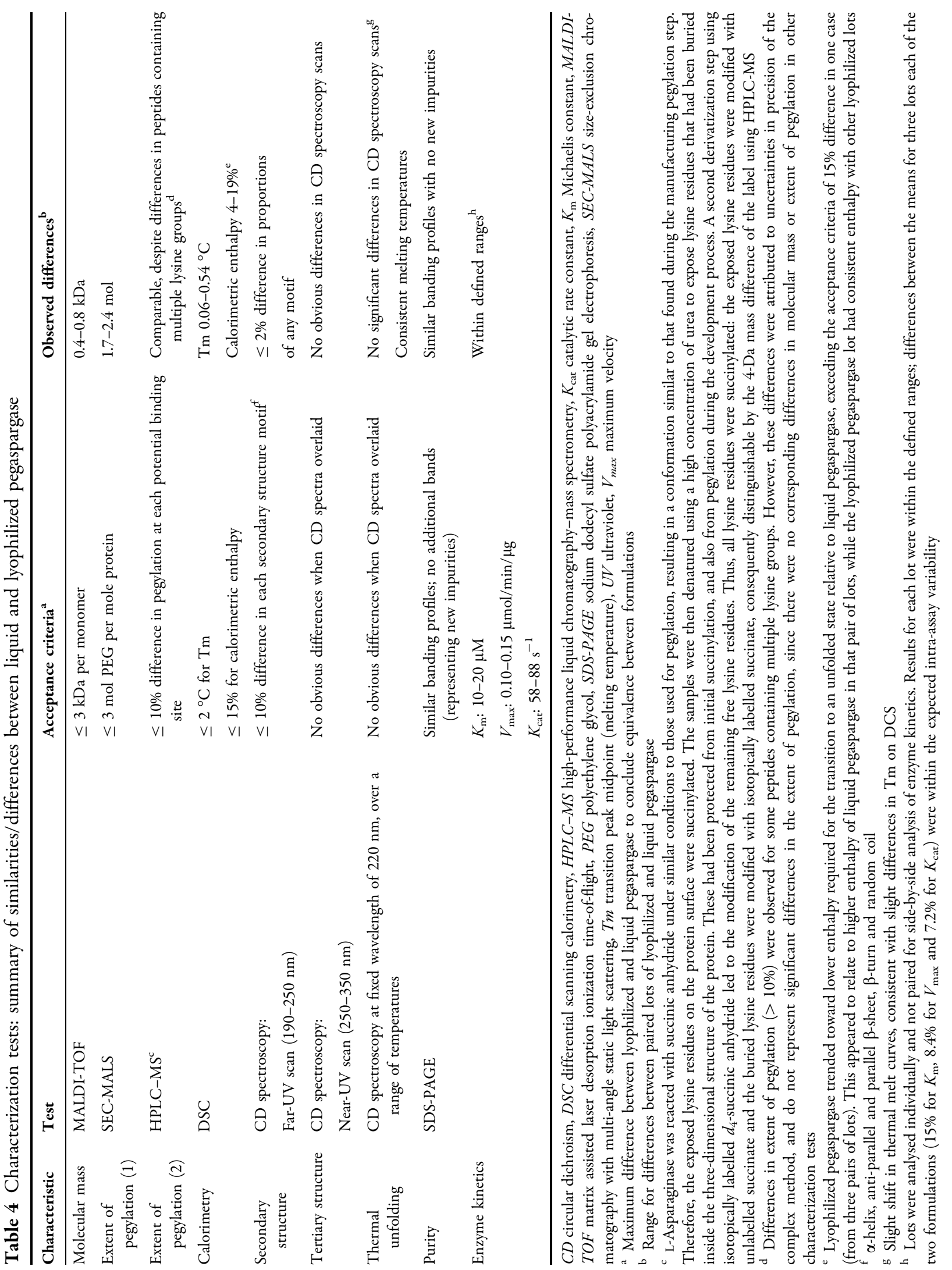



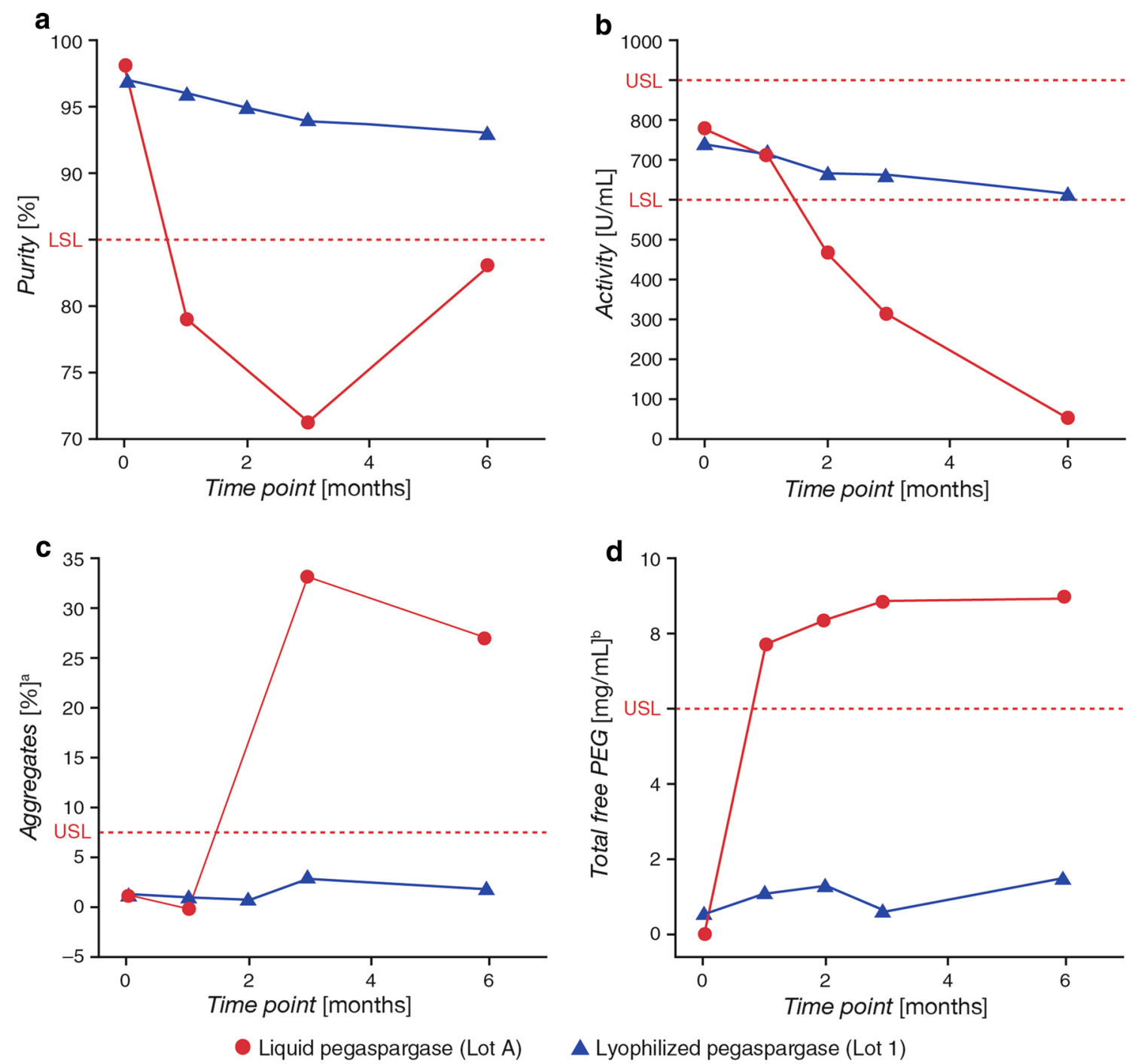

Fig. 2 Heat stress profiles for liquid (Lot A) and lyophilized (Lot 1) pegaspargase: purity (a), potency (b), aggregates (c) and total free PEG (d) of/in liquid and lyophilized pegaspargase stored at $40{ }^{\circ} \mathrm{C}$ for 6 months. ${ }^{a}$ Determined by GF-HPLC. ${ }^{b}$ Determined by RP-HPLC. Results from a representative lot of liquid and lyophilized pegaspargase are presented. Each lot was tested once at

Lyophilized pegaspargase (Lot 1)

each time point. Liquid and lyophilized lots were tested using validated methods. GF-HPLC gel filtration highperformance liquid chromatography, LSL lower specification limit, PEG polyethylene glycol, RP-HPLC reversedphase high-performance liquid chromatography, USL upper specification limit

pre- and post-lyophilized drug product, indicating that the lyophilization process used had no negative impact on product quality. Characterization tests showed that lyophilized pegaspargase also remained comparable to the liquid formulation, in terms of structure, extent and site of pegylation, and enzyme kinetics. DSC and CD spectroscopic investigation of

thermal unfolding revealed slight differences in enthalpy and melting point for the two formulations, which may relate to differences in salt and/or sucrose concentrations in excipients. Forced degradation tests demonstrated improved stability of lyophilized compared with liquid pegaspargase under conditions of heat stress. 

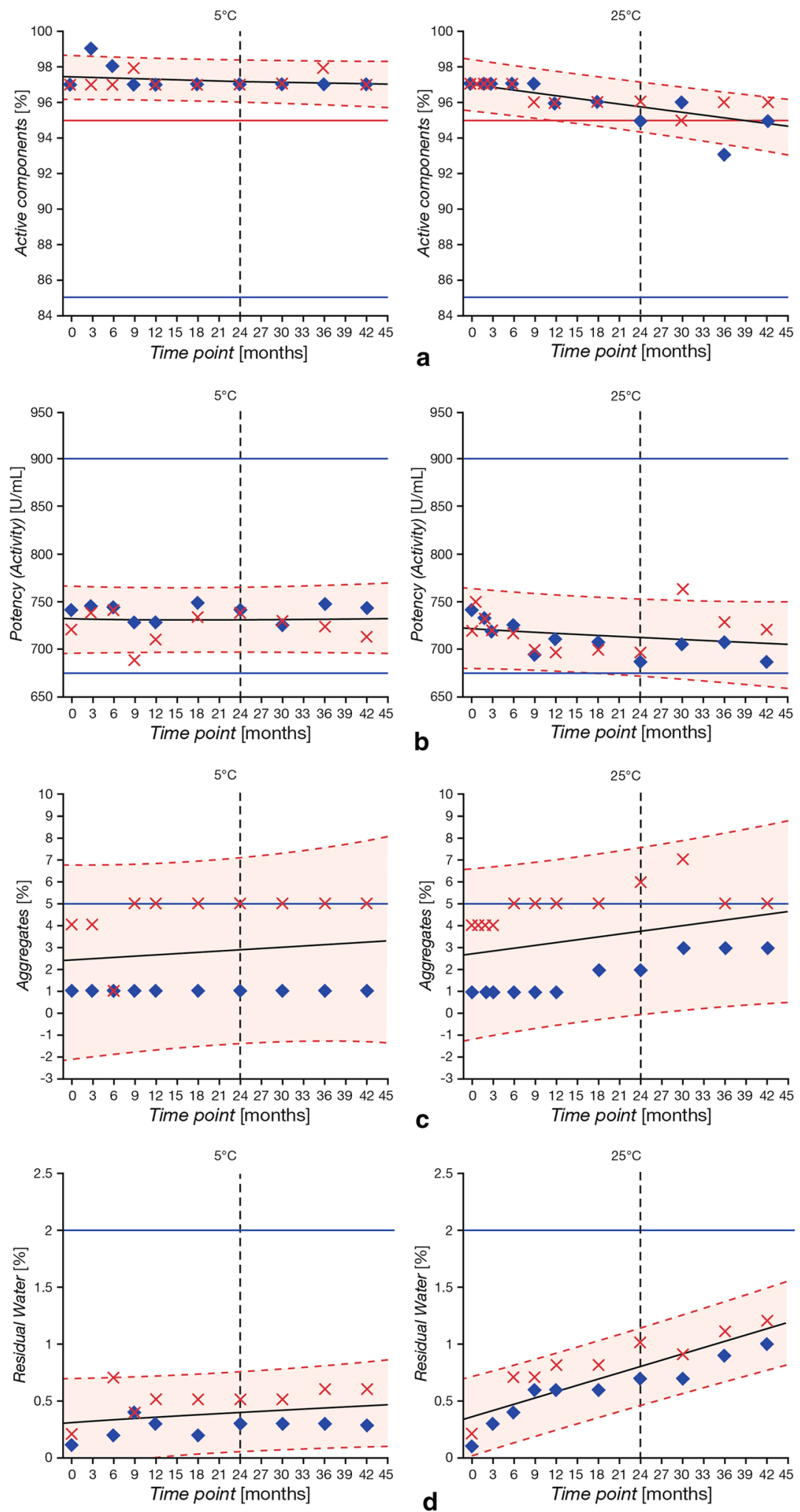

- Lot $1 \times$ Lot 3

Acceptance criteria (end of shelf life)

Acceptance criteria (on release of product)

- - - - End of stated shelf life 
4 Fig. 3 Stability of lyophilized pegaspargase stored at $5{ }^{\circ} \mathrm{C}$ and $25^{\circ} \mathrm{C}(60 \% \mathrm{RH})$ over 45 months: trend analyses for purity $(\mathbf{a})$, potency $(\mathbf{b})$, aggregates $(\mathbf{c})$ and residual water (d) substance for lyophilized pegaspargase. Lots stored in an inverted orientation. Results from a representative lot of liquid and lyophilized pegaspargase are presented. Each lot was tested once at each time point. Liquid and lyophilized lots were tested using validated methods. Acceptance criteria for purity (\% active components) are lower at end of shelf life than on release; acceptance criteria for other quality attributes (aggregates, potency, residual water) are the same at release and end of shelf life. $R H$ relative humidity

The primary aim of developing the lyophilized formulation of pegaspargase was to improve stability of the pegylated protein, allowing for a prolonged shelf life. From the long-term stability tests performed, we believe that this goal has been achieved. These tests demonstrated that lyophilized pegaspargase met acceptance criteria for various quality attributes, including purity, potency and protein aggregation, during a 45-month storage period under refrigerated conditions $\left(2-8{ }^{\circ} \mathrm{C}\right)$. Samples stored at $25^{\circ} \mathrm{C}$ (RH 60\%) had a greater tendency to absorb moisture, resulting in residual water in the lyophilized cake and potentially increasing the likelihood of cake collapse. In addition, these samples demonstrated a trend for slightly decreasing values in purity and potency and increasing aggregation over time. Active asparaginase is a tetramer, which becomes inactive when it disassembles into dimers or monomers over time and at higher temperatures, thereby resulting in a gradual decrease in potency [9]. It is therefore recommended that lyophilized pegaspargase should be refrigerated at $2-8{ }^{\circ} \mathrm{C}$ during longterm storage for optimal stability and maintenance of protein activity at the intended potency.

In light of the improved stability of lyophilized pegaspargase, while maintaining comparability with the liquid formulation in terms of physicochemical properties, purity and potency, the European Medicines Agency granted approval of lyophilized pegaspargase following a positive opinion from the Committee for Medicinal Products for Human Use [23]. On the basis of our results, the shelf life of lyophilized pegaspargase was set as 24 months at $2-8{ }^{\circ} \mathrm{C}$ [23]. This is a considerable improvement on the 8-month shelf life of liquid pegaspargase. As long-term stability has been demonstrated for test lots of lyophilized pegaspargase within a 45-month period, and tests are ongoing, it may be possible to extend this shelf life further in the future.

Lyophilization has been used to improve stability of other recombinant protein therapeutics, e.g. IgG1 monoclonal antibodies (mAbs) $[25,28,29]$, with potential applications including improved stability during shipping [29]. Tests of lyophilized IgG1 mAbs under simulated shipping conditions (agitation stress) suggested that lyophilized formulations can remain vulnerable to physical degradation on shaking [29]. However, we found no instability upon agitation for liquid or lyophilized pegaspargase.

One of the limitations of this study is that it did not investigate the stability of lyophilized pegaspargase following reconstitution. In a separate study, chemical and physical in-use stability has been demonstrated for $24 \mathrm{~h}$ for reconstituted solutions stored below $25^{\circ} \mathrm{C}$ [23]. Stability, in terms of enzyme activity based on catalysis of L-asparagine to L-aspartic acid and ammonia, has been reported for up to 7 days following reconstitution of a lyophilized formulation of native E. coli asparaginase in different parenteral solutions refrigerated at $2-8{ }^{\circ} \mathrm{C}$ [30]. It is important that sterility is maintained, so unless precautions are taken to preclude any risk of microbial contamination on reconstitution, it is recommended that the solution should be used immediately [23]. Another limitation is that each lot of liquid and lyophilized pegaspargase was tested once at each time point for each comparability assessment, using validated test methods. Characterization of liquid and lyophilized pegaspargase lots was performed in a side-by-side fashion, however, to minimize variability between assays. Finally, beyond demonstrating an effective example of stabilization, it could be argued that the information reported here may not be of broad applicability to the community, particularly 
without associated preclinical or clinical data for the lyophilized formulation.

Despite these limitations, the prolonged shelf life of lyophilized pegaspargase is expected to improve product supply management in pharmacy formulary settings through enabling greater flexibility and longer-term planning. The prolonged shelf life may also lead to improvements in access to pegaspargase for patients with ALL in countries where liquid pegaspargase is currently not available.

\section{CONCLUSION}

Lyophilization has been demonstrated to improve the stability of pegaspargase without altering other physicochemical properties, permitting a prolonged shelf life of 24 months at $2-8{ }^{\circ} \mathrm{C}$.

\section{ACKNOWLEDGEMENTS}

This study was conducted by Sigma-Tau Pharmasource (now Exelead, Indianapolis, IN, US), reported by Sigma-Tau Pharmaceuticals (now Leadiant Biosciences, Inc Gaithersburg, MD, US), and funded by the Sponsor, Baxalta (now part of Takeda).

Funding. Publication costs, including article processing charges and the Open Access fee were funded by Servier Affaires Médicales, Suresnes, France. All authors had full access to all of the data in this study and take complete responsibility for the integrity of the data and accuracy of the data analysis.

Authorship. All named authors meet the International Committee of Medical Journal Editors (ICMJE) criteria for authorship for this article, take responsibility for the integrity of the work as a whole, and have given their approval for this version to be published.

Medical Writing, Editorial and Additional Assistance. David Bollag (Servier) and Kim Brown, Alicia Jeannotte, Susan Wieting, Bruce Tangarone and Anna Wijatyk (Shire employees at the time of the study) provided valuable advice and assistance during the preparation of this manuscript. Chris Lockey, a former employee of Baxalta (now part of Takeda) and Sigma-Tau Pharmasource (now Exelead, Indianapolis, IN, US), was instrumental in leading the development process detailed in this manuscript. Medical writing support was provided by Laura McMahon of Physicians World Europe GmbH (Mannheim, Germany), and funded by Shire, Zurich, Switzerland (now part of Takeda) and Servier Affaires Médicales, Suresnes, France.

Disclosures. Alexander Faschinger was an employee of Shire (now part of Takeda) at the time of the reported analyses and is currently an employee of Servier; Nicole Sessler is an employee of Baxalta Innovations Gmbh (now part of Takeda).

Compliance with Ethics Guidelines. This article does not contain any studies with human participants or animals.

Data Availability. Data are the proprietary property of Shire and Servier and access may be requested by contacting Servier's legal representative.

Open Access. This article is distributed under the terms of the Creative Commons Attribution-NonCommercial 4.0 International License (http://creativecommons.org/licenses/ by-nc/4.0/), which permits any noncommercial use, distribution, and reproduction in any medium, provided you give appropriate credit to the original author(s) and the source, provide a link to the Creative Commons license, and indicate if changes were made.

\section{REFERENCES}

1. Alvarnas JC, Brown PA, Aoun P, et al. Acute lymphoblastic leukemia, version 2.2015. J Natl Compr Cancer Netw. 2015;13(10):1240-79.

2. Hoelzer D, Bassan R, Dombret H, et al. Acute lymphoblastic leukaemia in adult patients: ESMO 
clinical practice guidelines for diagnosis, treatment and follow-up. Ann Oncol. 2016;27(suppl 5):v69-82.

3. Piatkowska-Jakubas B, Krawczyk-Kulis M, Giebel S, et al. Use of L-asparaginase in acute lymphoblastic leukemia: recommendations of the Polish Adult Leukemia Group. Pol Arch Med Wewn. 2008;118(11):664-9.

4. Pieters R, Hunger SP, Boos J, et al. L-Asparaginase treatment in acute lymphoblastic leukemia: a focus on Erwinia asparaginase. Cancer. 2011;117(2):238-49.

5. Jazz Pharmaceuticals Inc. Erwinase ${ }^{\circledR}$ Highlights of Prescribing Information 2016. https://erwinaze. com/ERWINAZEPI.pdf. Accessed Dec 2017.

6. Barnes WR, Dorn GL, Vela GR. Effect of culture conditions on synthesis of L-asparaginase by Escherichia coli A-1. Appl Environ Microbiol. 1977;33(2):257-61.

7. Jennings MP, Beacham IR. Co-dependent positive regulation of the ansB promoter of Escherichia coli by CRP and the FNR protein: a molecular analysis. Mol Microbiol. 1993;9(1):155-64.

8. Roberts J, Burson G, Hill JM. New procedures for purification of L-asparaginase with high yield from Escherichia coli. J Bacteriol. 1968;95(6):2117-23.

9. Wriston JC Jr, Yellin TO. L-Asparaginase: a review. Adv Enzymol Relat Areas Mol Biol. 1973;39:185-248.

10. Netrval J. Effect of organic and amino acids on Lasparaginase production by Escherichia coli. Arch Mikrobiol. 1973;92(4):345-52.

11. Dinndorf PA, Gootenberg J, Cohen MH, Keegan P, Pazdur R. FDA drug approval summary: pegaspargase (Oncaspar) for the first-line treatment of children with acute lymphoblastic leukemia (ALL). Oncologist. 2007;12(8):991-8.

12. Borghorst S, Hempel G, Poppenborg S, Franke D, Konig T, Baumgart J. Comparative pharmacokinetic/pharmacodynamic characterisation of a new pegylated recombinant E. coli L-asparaginase preparation (MC0609) in Beagle dog. Cancer Chemother Pharmacol. 2014;74(2):367-78.

13. Rau RE, Dreyer Z, Choi MR, et al. Outcome of pediatric patients with acute lymphoblastic leukemia/lymphoblastic lymphoma with hypersensitivity to pegaspargase treated with PEGylated Erwinia asparaginase, pegcrisantaspase: a report from the Children's Oncology Group. Pediatr Blood Cancer. 2018;65(3):e26873.
14. Chien WW, Allas S, Rachinel N, et al. Pharmacology, immunogenicity, and efficacy of a novel pegylated recombinant Erwinia chrysanthemiderived L-asparaginase. Invest New Drugs. 2014;32(5):795-805.

15. Rizzari C, Conter V, Stary J, Colombini A, Moericke A, Schrappe M. Optimizing asparaginase therapy for acute lymphoblastic leukemia. Curr Opin Oncol. 2013;25(Suppl 1):S1-9.

16. Asselin BL, Whitin JC, Coppola DJ, Rupp IP, Sallan SE, Cohen HJ. Comparative pharmacokinetic studies of three asparaginase preparations. J Clin Oncol. 1993;11(9):1780-6.

17. Park YK, Abuchowski A, Davis S, Davis F. Pharmacology of Escherichia coli-L-asparaginase polyethylene glycol adduct. Anticancer Res. 1981;1(6):373-6.

18. Patel N, Krishnan S, Offman MN, et al. A dyad of lymphoblastic lysosomal cysteine proteases degrades the antileukemic drug L-asparaginase. J Clin Invest. 2009;119(7):1964-73.

19. Avramis VI, Sencer S, Periclou AP, et al. A randomized comparison of native Escherichia coli asparaginase and polyethylene glycol conjugated asparaginase for treatment of children with newly diagnosed standard-risk acute lymphoblastic leukemia: a Children's Cancer Group study. Blood. 2002;99(6):1986-94.

20. Würthwein G, Lanvers-Kaminsky C, Hempel G, et al. Population pharmacokinetics to model the time-varying clearance of the PEGylated asparaginase Oncaspar ${ }^{\circledR}$ in children with acute lymphoblastic leukemia. Eur J Drug Metab Pharmacokinet. 2017;42(6):955-63.

21. Turecek PL, Bossard MJ, Schoetens F, Ivens IA. PEGylation of biopharmaceuticals: a review of chemistry and nonclinical safety information of approved drugs. J Pharm Sci. 2016;105(2):460-75.

22. Dozier JK, Distefano MD. Site-specific PEGylation of therapeutic proteins. Int J Mol Sci. 2015;16(10):25831-64.

23. Shire Pharmaceuticals. Oncaspar summary of product characteristics 2017. http://www.ema.europa. eu/docs/en_GB/document_library/EPAR_-_Product_ Information/human/003789/WC500200735.pdf. Accessed December 2017.

24. Remmele RL, Krishnan S, Callahan WJ. Development of stable lyophilized protein drug products. Curr Pharm Biotechnol. 2012;13(3):471-96.

25. Davis JM, Zhang N, Payne RW, et al. Stability of lyophilized sucrose formulations of an IgG1: 
subvisible particle formation. Pharm Dev Technol. 2013;18(4):883-96.

26. Carpenter JF, Randolph TW, Jiskoot W, et al. Overlooking subvisible particles in therapeutic protein products: gaps that may compromise product quality. J Pharm Sci. 2009;98(4):1201-5.

27. Braun A, Kwee L, Labow MA, Alsenz J. Protein aggregates seem to play a key role among the parameters influencing the antigenicity of interferon alpha (IFN-alpha) in normal and transgenic mice. Pharm Res. 1997;14(10):1472-8.

28. Murphy BM, Zhang N, Payne RW, et al. Structure, stability, and mobility of a lyophilized IgG1 monoclonal antibody as determined using secondderivative infrared spectroscopy. J Pharm Sci. 2012;101(1):81-91.

29. Telikepalli S, Kumru OS, Kim JH, et al. Characterization of the physical stability of a lyophilized IgG1 $\mathrm{mAb}$ after accelerated shipping-like stress. J Pharm Sci. 2015;104(2):495-507.

30. Stecher AL, de Deus PM, Polikarpov I, Abrahão-Neto J. Stability of L-asparaginase: an enzyme used in leukemia treatment. Pharm Acta Helv. 1999;74(1):1-9. 